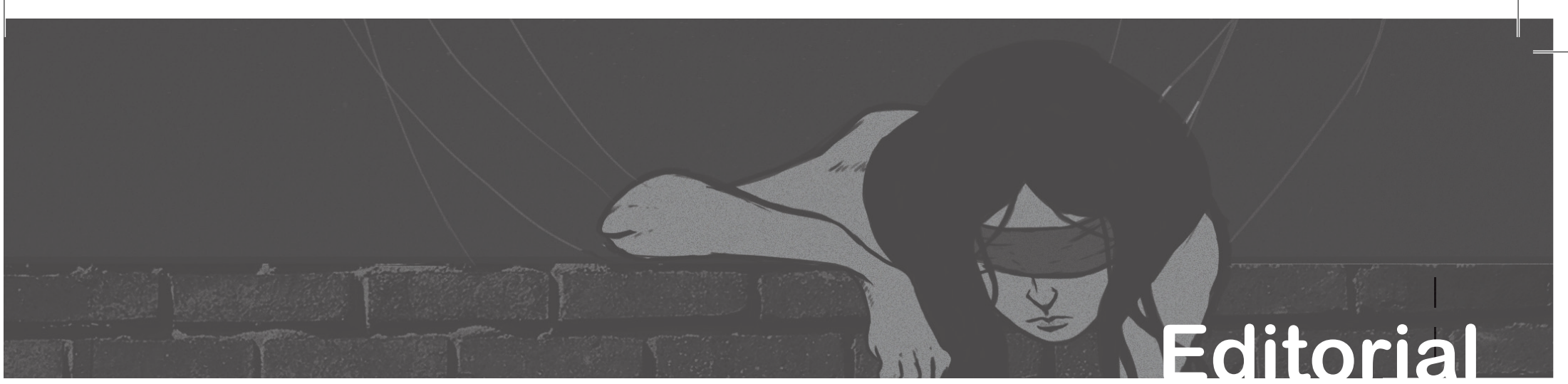

\title{
Conocimiento Latinoamericano y Globalización: Retos para la investigación y las publica- ciones en América Latina
}

Para Latinoamérica es innegable la brecha entre la ciencia, la tecnología y la innovación y el desarrollo productivo y social de sus naciones, ocasionada, entre otros factores, por la internacionalización del conocimiento. Esta "apertura" ha conducido a que el saber en América Latina enfrente grandes retos y desafíos en temas relacionados con los sistemas de investigación y publicación de sus países. Menciono brevemente algunos de ellos.

Primero. Si bien el avance de las nuevas tecnologías de la información se ha convertido, para algunos, en una posibilidad de producción, almacenamiento y trasmisión de conocimientos, de "interconexión entre comunidades científicas", la realidad no deja de mostrarnos que tal competitividad tecnológica puede ampliar aún más las diferencias "entre los que tienen y no tienen, entre los que saben y los que no sabe" (Vessuri, 2003). Las nuevas tecnologías son un punto de avance cuando se tiene acceso a ellas, cuando se puede invertir en el desarrollo tecnológico; sin embargo, Latinoamérica ha mostrado dificultades importantes en los temas relacionados con la inversión en ciencia y tecnología, pues representa apenas el $1 \%$ de los gastos mundiales y el $1.4 \%$ de la producción cientííca mundial. El peso tecnológico mundial de América latina, medido a través de las patentes solicitadas, es solamente del 0.2\% (Lema, 2004). Competitivamente, esto reduce la capacidad de desarrollos equitativos entre países y conduce, en muchos casos, a un "mirar de lejos" tales avances tecnológicos.

Segundo. El fenómeno de "brain drain”, o de migraciones unidireccionales de cientíiticos hacia los países industrializados, ha dejado claro que éste representa una pérdida de conocimiento muy importante para los países en desarrollo. Sobretodo por lo que significa en términos de "inversión educativa". Algunos de nuestros países, como Argentina y Colombia, han adoptado en sus sistemas de ciencia y tecnología medidas para mitigar el impacto de esta migración, a través de programas como la diáspora de conocimiento, bajo la esperanza de que los ahora llamados "brain gain" retribuyan la mencionada inversión a sus países de origen a través de la transmisión de sus conocimientos, experiencias y capacidades de innovación adquiridas o ganadas en los países desarrollados. Sin embargo, no siempre se consiguen los resultados esperados y, en los casos de diásporas eficaces, se necesita tiempo para ver los efectos económicos y sociales de la replicación (dejando igualmente de lado discusiones sobre el efecto de "replicar" y la falta de conocimientos endógenos para el avance de la ciencia mundial).

Tercero. La competencia en ciencia, tecnología e innovación entre países ha ocasionado serios efectos en las dinámicas de representación del conocimiento. Los países con bajos desarrollos en estas áreas buscan desesperadamente ajustarse a los adelantos de las naciones con avances de este tipo, a través de lo que algunos podrían 
denominar "pérdida de identidad cultural" (Carrizo, 2005), tanto interna a las regiones, como entre las naciones latinoamericanas. Los lineamientos internacionales de investigación, impuestos por los países desarrollados, han conducido a un posicionamiento, en muchas de nuestras naciones, de nuevas elites que intervienen, administran y regulan los procesos de difusión de experiencias y conocimientos. Estas elites, cuyo papel está en el mantenimiento de los discursos del conocimiento (de quién conoce y cómo se conoce), han provocado que, en algunos casos, se privilegie el deseo de unos pocos en detrimento del de muchos.

Cuarto. Para el caso de las publicaciones, los procesos de categorización de revistas han conducido a que en nuestros países se lleve a cabo un proceso de selección "innatural" de partícipes y actores. Actualmente, los autores de artículos de investigación se debaten, movidos por las implicaciones económicas de las políticas universitarias, entre publicar en revistas con una alta categorización (mejor pagas por las universidades pero con menor probabilidad de salida), o publicar más artículos en revistas con baja categorización (menos pagas por las universidades pero con más posibilidades de salida). Por lo menos, en Colombia, el número de revistas con un alto índice de categorización es bastante bajo, lo que aumenta el poder de las elites cuando de seleccionar artículos (autores/ universidades) se trata.

Todo este panorama conduce, necesariamente, al planteamiento de soluciones que permitan enfrentar los retos del conocimiento en América Latina. Algunas de estas alternativas son: 1. consolidación de estructuras científico-técnicas con las cuales se analicen y resuelvan especialmente las dificultades endógenas de las naciones. Esto significa avanzar en ciencia y tecnología para resolver problemas sociales pero a través de inversión en la misma ciencia y tecnología; 2. el control de la migración de los científicos investigadores o de reajustes del aprovechamiento de tales tránsitos a través de las diásporas de difusión de experiencias, conocimientos y capacidades de innovación hasta logrado que el crecimiento endógeno permita asumir los desafíos del futuro de las naciones latinoamericanas. 3. Superar las barreras de las elites erigidas para la selección y mantenimiento de los grupos de conocimiento, de "qué se sabe y quienes pueden saberlo", a través de programas y redes de cooperación abierta y de difusión libre del conocimiento, lo cual requiere la colaboración productiva de los países latinoamericanos para el apoyo en investigación y publicación. 5. consolidación de redes para la integración regional e internacional de los diversos componentes del conocimiento que supere los intereses de las élites en cuanto a socialización del conocimiento, a través de sistemas de acceso libre, como los generados por los programas de Creative Commons. Ejemplo de ello son el sistema de "Open Education” y el "Open Knowledge Repository”.

Latinoamérica se encuentra en un momento crítico para el avance de la ciencia y la tecnología. Es indudable el esfuerzo que en Colombia viene realizando el Sistema Nacional de Ciencia y Tecnología COLCIENCIAS para fomentar la investigación y la calidad de las publicaciones, al igual que para mitigar el impacto de las migraciones del conocimiento y de la comercialización indebida del conocimiento. También sabemos ahora que la generación de conocimiento científico y técnico ya no es una actividad exclusivamente académica, sino que, por el contrario, propone nuevas dinámicas a las sociedades latinoamericanas de "economía y negociación" de saberes. Deviene de lo anterior nuevos riesgos para los pequeños países en términos de competitividad en la nueva sociedad del conocimiento, en donde la falta de una adecuada inversión, la ausencia de definiciones estratégicas claras para los avances en ciencia, tecnología e innovación, y la poca articulación de éstas con el desarrollo social afectan significativamente a nuestras naciones. 
Desde la revista Panorama hemos querido continuar con la tradición de mostrar los avances de nuestros países en términos de ciencia, de estrategias educativas que le apuestan a la innovación y al uso de las nuevas tecnologías. En este nuevo número presentaremos, especialmente, las voces de nuestros colegas en Colombia, Perú y Bolivia. Invito a nuestros lectores a conocer estas formas de conocimiento.

Jaime Castro Martínez

Editor científico

\section{Referencias sugeridas}

Carrizo, Luis (2005). Internacionalización del conocimiento: El impacto de la globalización en la educación superior. Observatorio de Reformas Universitarias.

Lema, Fernando (2004). La construcción de la sociedad del conocimiento en América Latina. La diáspora del conocimiento. Santiago de Chile: Instituto de Estudios Avanzados, Universidad de Santiago de Chile.

Vessuri, Hebe (2003). La Ciencia y la Educación Superior en el proceso de internacionalización. Elementos de un marco conceptual para América Latina. UNESCO Forum Occasional, 3, 19. 